\title{
A study on cardiovascular disease risk factors among faculty members of a tertiary care teaching institute of Kolkata
}

\author{
Sita Chattapadhyay ${ }^{1}$, Sachita Saha ${ }^{2, *}$, Mausumi Basu $^{3}$, Raghunath Misra ${ }^{4}$ \\ ${ }^{\mathbf{1}}$ Associate Professor, ${ }^{2,3}$ Assistant Professor, ${ }^{4}$ Professor \& HOD, ${ }^{1,3,4}$ Dept. of Community Medicine, ${ }^{2}$ Dept. of General Medicine, \\ ${ }^{1}$ K. P. C. Medical College, Kolkata, West Bengal, ${ }^{2,3,4}$ IPGMER and SSKM Hospital, Kolkata, West Bengal, India
}

*Corresponding Author:

Email: saha_sanchita2000@rediffmail.com

\begin{abstract}
Introduction: Medical faculty knows CVD risk factors and their prevention very well; despite risk assessment and disease prevention efforts are lacking in this group due to their busy schedule and stress.

Objectives: To assess the prevalence and types of cardiovascular risk factors among faculty members of a tertiary care teaching hospital of Kolkata.

Materials and Method: An Institution based cross sectional study was conducted among 246 faculty members using a pre designed structured questionnaire based on WHO STEPS Instrument from 5th March-4th April, 2018.

Results: About $94 \%$ faculty members had one or more cardiovascular risk factors and different types of cardiovascular risk factors were :male gender(67.48\%), smoking(11.38\%), alcohol consumption(15.04\%), fast food(13.14\%), junk food(11.50\%)\& cold drink (17.49\%)intake, stress in last one year(40.65\%), family history of CVD(19.51\%), overweight \& obesity(35.37\%), pre hypertension(72.36\%) \& hypertension( $8.94 \%)$, diabetes(9.76\%), and high cholesterol.

Conclusions: This small special group survey adds on the risk factors prevalent in the medical set-up and thus focuses the attention of cardiovascular epidemiologist and researcher to conduct more studies.
\end{abstract}

Keywords: Cardiovascular, Risk factors, Faculty.

\section{Introduction}

Cardiovascular diseases (CVDs) consists of a group of diseases of heart and blood vessels which includecoronary artery disease; valvular heart disease; rheumatic heart disease; congenital heart disease; cerebrovascular disease; peripheral arterial disease; and Others - deep vein thrombosis etc. ${ }^{1}$

As per WHO, the most important behavioral risk factors of CVDs are unhealthy diet, physical inactivity, tobacco use and excessive alcohol intake. The effects of these behavioral risk factors show up in individuals as increased blood pressure, raised blood glucose, high blood lipids, overweight $\&$ obesity. ${ }^{1}$

As an individual level, cessation of tobacco use, reduction of salt in the diet, consuming fruits and vegetables, regular physical activity and avoiding harmful use of alcohol reduce the risk of cardiovascular disease. In addition, detection \& drug treatment of diabetes, hypertension and hypercholesterolaemia is necessary to reduce cardiovascular risk. ${ }^{1}$

Globally, CVDs are the leading 1 killer; more people die from CVDs than from any other cause annually. ${ }^{2}$ An estimated 17.7 million people die from CVDs each year globally, which is $31 \%$ of all deaths. Among this deaths, about 7.4 million are due to coronary heart disease and 6.7 million were due to stroke. ${ }^{2}$ It is anticipated that CVD death will rise to 23.6 million by $2030 .^{2}$

The striking features of CVD in India are high mortality rates, premature CVDs and increasing burden. ${ }^{3}$ The Global Burden of Disease study estimates ageadjusted CVD mortality rate of 272/100 000 population in India which is higher than the global average of 235/100000 population. ${ }^{4}$ An increasing trend in proportional CVD death has been observed in India, with $20.6 \%$ of all deaths in $1990,21.4 \%$ in $1995,24.3 \%$ in $2000,27.5 \%$ in 2005 , and $29.0 \%$ in $2013 .^{5}$

People with CVDs or who are at high cardiovascular risk due to one or more risk factors need early detection and management using lifestyle change, counselling, monitoring and medications, as appropriate. ${ }^{2}$

Medical faculty knows CVD risk factors and their prevention very well; despite risk assessment and disease prevention efforts are lacking in this group due to their busy schedule and stress. Although Western data has identified relationship of various occupational groups and cardiovascular diseases risk factors, local data is scarce in this field.

With this background a study was conducted on cardiovascular disease risk factors among faculty members of a tertiary care teaching Hospital of Kolkata.

\section{Materials and Method}

Type of study, study design, study setting \& period, study population: An Institution based descriptive observational study, cross sectional in design was carried out among Faculty members of a tertiary care teaching Institute of Kolkata from 5th March-4th April, 2018.

Inclusion criteria: Faculty members of
a. All ages
b. Both gender
c. Present during data collection period
d. Gave informed verbal consent to participate in the study 
a. Exclusion criteria: a) Those who were not willing

b) Those who were not available during data collection period

Study tools: A predesigned pre -tested structured self report questionnaire, based on WHO STEPS instrument. $^{6}$

The questionnaire had four parts. Part I consisted of information on the socio-demographic status; Part II consisted of risk factors of cardiovascular diseases, Part III consisted of physical measurements, and Part IV dealt with biochemical measurements of the study population. Study variables: Age(in completed years), gender, religion, marital status, highest education, designation, department, residence, type of family, per capita monthly income (PCMI) as per Modified B. G. Prasad Scale $2017,{ }^{7}$ family history of CVDs among first degree relatives, smoking status, alcohol consumption, habit of exercise, vigorous \& moderate intensity activity, type of cooking oil, intake of soft drinks, fast food, junk food, fruits, vegetables, stress during last one year, OCP use among female study population, weight, height, BMI, waist circumference, hip circumference, waist/hip ratio, B.P. level, Fasting blood glucose \& Total cholesterol.

The prevalence of cardiovascular disease risk factors were ascertained from self-reported data, physical and bio-chemical measurements.

Sample size \& sampling technique: The sample size of 246 faculty members was calculated with absolute precision of $5 \%$ at $95 \%$ confidence level, using the prevalence rate $(80 \%)$ of any risk factors for NCDs found out during the pilot study. The faculty members were selected by simple random sampling technique.

Data collection technique: Study population were informed about the purpose and nature of the study; their informed verbal consent was taken where confidentiality and anonymity were assured in all aspects. Then the questionnaire was administered to them to fill out the questions. If a faculty could not be contacted during three separate visits, he/she was considered as a nonrespondent.

\section{Statistical Analysis}

Data were double checked and entry in Microsoft Office Excel 2010(Microsoft Corp., Redmond, WA, USA) and validated by a second observer.

For descriptive statistics: Frequency(n) and proportion (95\% confidence interval) was calculated and presented by suitable tables $\&$ figures.

Software for statistical analysis: SPSS version 20.

\section{Operational definition}

1. Socio-economic Classification: According to Modified B.G. Prasad's scale Jan, $2017^{7}$

\begin{tabular}{|l|c|}
\hline \multicolumn{1}{|c|}{ Social Class } & PCMI (Rs.) \\
\hline Upper & $(>=6254)$ \\
\hline Upper middle & $(3127-6253)$ \\
\hline
\end{tabular}

\begin{tabular}{|l|c|}
\hline Middle & $(1876-3126)$ \\
\hline Lower middle & $(938-1875)$ \\
\hline Lower & $(<938)$ \\
\hline
\end{tabular}

2. Current smoker: Defined as persons who reported smoking at least 100 cigarettes in their lifetime and who, at the time of survey, smoked either every day or some days(CDC). ${ }^{8}$

3. Former smoker: Who reported smoking at least 100 cigarettes in their lifetime and who, at the time of the survey, did not smoke at all. ${ }^{8}$

4. Standard Alcoholic drink:

a. $250 \mathrm{ml}$ of beer.

b. $100 \mathrm{ml}$ of wine.

c. $30 \mathrm{ml}$ distilled spirits or liquor (e.g., gin, rum, vodka, or whisky)

5. Fast food: Food that can be prepared and served very quickly. Examples are pizza, burger, rolls, samosa etc.

6. Junk food: Prepared or packaged food that has low nutritional value. Examples are candy, chips etc.

7. Soft drink: A refreshing beverage that is usually composed of water, artificial sweetener, and a flavoring agent (pepsi, sprite etc.).

8. Choice of cooking oil: Combination of 2 or more vegetable oils. ${ }^{9}$

9. Body mass index (BMI): Classification of adults $(\text { WHO })^{10}$ : Defined as weight in Kilogram divided by the square of height in meters $(\mathrm{kg} / \mathrm{m} 2)$
a. $\quad<18.50$ (Underweight)
b. 18.50-24.99(Normal range)
c. 25.00-29.99 (Pre obese)
d. 30.00-34.99(Obese class I)
e. $35.00-39.99$ (Obese class II)
f. $>=40.00$ (Obese class III)

10. Waist circumference measurement: midpoint between the lower margin of the last palpable rib and the top of the iliac crest in the mid axillary line using non stretchable flexible tape.

WHO cut off points of WC for measurement of overweight and obesity: ${ }^{11}$

\begin{tabular}{|l|c|}
\hline \multicolumn{1}{|c|}{ WC } & Cut off points \\
\hline Men & $102 \mathrm{~cm}$ \\
\hline Women & $88 \mathrm{~cm}$ \\
\hline
\end{tabular}

11. Hip Circumference: measured around the widest portion of the buttocks, at the level parallel to the floor.

Waist-Hip ratio(W/H): Ratio of the circumference of the waist to that of the hips.

WHO cut off points of W-H ratio for measurement of abdominal obesity: ${ }^{11}$

\begin{tabular}{|l|c|}
\hline \multicolumn{1}{|c|}{ W-H ratio } & Cut off points \\
\hline Men & $>=1.00$ \\
\hline Women & $>=0.85$ \\
\hline
\end{tabular}




\section{Blood Pressure cut offs as per JNC 8: ${ }^{12}$}

\begin{tabular}{|l|c|c|}
\hline BP classification & SBP $\mathbf{~ m m ~ H g}$ & DBP $\mathbf{~ m m ~ H g}$ \\
\hline Normal & $<120$ & $<80$ \\
\hline Prehypertension & $120-139$ & $80-89$ \\
\hline Stage1 hypertension & $140-159$ & $90-99$ \\
\hline Stage2 hypertension & $>=160$ & $>=100$ \\
\hline
\end{tabular}

13. High cholesterol: One who have been diagnosed with high blood cholesterol (total serum cholesterol level $>=240$ $\mathrm{mg} / \mathrm{dl}$ ) during the survey and who did not report using cholesterol lowering medication. 14.

\begin{tabular}{|l|c|}
\hline \multicolumn{1}{|c|}{ Total Cholesterol } & Category \\
\hline Below $200 \mathrm{mg} / \mathrm{dl}$ & Ideal \\
\hline From $200-239 \mathrm{mg} / \mathrm{dl}$ & Borderline High \\
\hline $240 \mathrm{mg} / \mathrm{dl}$ and over & High \\
\hline
\end{tabular}

15. High Blood sugar:The WHO recomendation for the diagnostic criteria for diabetes: ${ }^{13}$

a. Fasting plasma glucose -- >=126 mg/dl

b. 2 hour plasma glucose-- $>200 \mathrm{mg} / \mathrm{dl}$

16. The steps instrument (version 3.2) ${ }^{6}$ : The tool used to collect data and measure noncommunicable disease (NCD) risk factors within the WHO STEP wise approach to surveillance is called the STEPS Instrument.

The STEPS Instrument covers three different levels or 'steps' of risk factor assessment:

-Step 1 (questionnaire),

-Step 2 (physical measurements) and

-Step 3 (biochemical measurements)

17. Examples of physical activity ${ }^{14}$

\begin{tabular}{|l|l|}
\hline $\begin{array}{l}\text { Moderate Intensity physical activity } \\
\text { (approximately 3-6 METs) Requires } \\
\text { a moderate amount of effort \& } \\
\text { noticeable accelerates the heart rate }\end{array}$ & $\begin{array}{l}\text { Vigorous Intensity physical activity } \\
\text { (approximately >6 METs) Requires } \\
\text { a large amount of effort \& a } \\
\text { substantial increase in heart rate }\end{array}$ \\
\hline Brisk walking & Running \\
\hline Dancing & Walking / climbing briskly up a hill \\
\hline Gardening & Fast cycling \\
\hline Housework and domestic chores & Fast swimming \\
\hline Carrying moderate loads & Carrying heavy loads \\
\hline
\end{tabular}

One MET is defined as the energy cost of sitting quietly-a person's caloric consumption is three to six times higher when being moderately active (3-6 METs) and more than six times higher when being vigorously active ( $>6$ METs)

For moderate-intensity physical activity, a person's target heart rate should be 50 to $70 \%$ of his or her maximum heart rate. For vigorous-intensity physical activity, a person's target heart rate should be 70 to $85 \%$ of his or her maximum heart rate

18. First degree relative: A first-degree relative is defined as a close blood relative --includes the individual's parents, full siblings, or children.

19. Scoring of Cardiovascular risk factors: Cardiovascular risk factor positive faculty was defined on the basis of self-report, physical and biochemical measurement.

We have identified 15 risk factors; if the risk factor was present, it was scored $1 \&$ if absent, scored 0 ; so the total score range was between 0 to 15 .Thus we grouped faculty members by number of risk factors present.

\section{Result}

Table 1 demonstrated socio demographic profile of the study population which showed that $44.30 \%$ were between $35-44$ years of age group, $67.48 \%$ were males, $82.11 \%$ were Hindu , $90.24 \%$ were married, $76.01 \%$ had the highest education of MD, $99.19 \%$ belonged to urban residence, $87.80 \%$ were from nuclear family, most of them were of upper socio economic class, $34.56 \%$ were demonstrators.

Among 35 departments of IPGME\&R and SSKM Hospital, we were able to collect data from only 15 departments, majority were collected from anatomy \& orthopaedic surgery department and least from cardiology and ophthalmology department [Table 2].

About $11.38 \%$ of the study population were current smoker; of which $17.86 \%$ smoked more than 10 cigarettes per day; \& $50 \%$ smoked for more than last 20 
years, $15.04 \%$ consumed alcohol in any occasion during last 12 months; among them $5.40 \%$ took alcohol once in a week \&18.92\% drinker consumed $>90 \mathrm{ml}$ in one sitting, $13.14 \%, 11.50 \%$ and $17.49 \%$ took fast food, junk food \&soft drinks 4-7 days per week respectively, $0.82 \%$ of study population ate no fruits \& $96.34 \%$ took vegetables for $4-7$ days in a week, $40.65 \%$ \& $89.43 \%$ of the study population did vigorous $\&$ moderate intensity activity respectively, among those who did vigorous intensity activity;28\% did it for 10-30 minutes/day, similarly among those who did moderate intensity activity $48.64 \%$ did it for 30minutes/day,51.53\% participants walked for at least 5 days in a week\& $10.68 \%$ walked 30 for min/day, $40.65 \%$ faculty faced any stressful event during last one year, $19.51 \%$ had family history of CHD among their 1st degree relatives, among female faculty, $5.40 \%$ used OCP any time during their reproductive period, $48.67 \%$ used combination of 2 vegetable oils for household cooking and 9.73\%, 10.61\% \& $14.16 \%$ self -reported history of diabetes, hypertension and high cholesterol respectively [Table 3].

Table 4 described that $\mathbf{2 . 8 5 \%}$ of the study population were obese class 1 , another $32.52 \%$ were pre obese as per WHO scale (thus combined overweight \& obesity was $35.37 \%$ ),26.51\% male study population had a waist circumference of more than $102 \mathrm{~cm}$ while $30.00 \%$ female study population had a waist circumference of more than $88 \mathrm{~cm}$, similarly $19.88 \%$ of male study population had a waist/hip of more than 1.00 $\& 40.00 \%$ of the female study population had a waist/hip ratio of more than 0.85 , about $8.13 \%$ were Hypertensive class $1,0.81 \%$ were hypertensive class 2 , and $72.36 \%$ had pre hypertension.

About $9.76 \%$ of the study population were diabetic $\& 8.94 \%$ were pre- diabetic. About $85.77 \%$ of faculty members had normal total cholesterol level and $14.23 \%$ had borderline cholesterol level [Table 5].

Table 6 showed that almost $94.31 \%$ faculty members had any or other cardiovascular risk factors; of which $86.59 \%$ had 1-5 numbers of risk factors, $6.91 \%$ had 6-10 of risk factors and $0.81 \%$ had high numbers of cardiovascular risk factors. However $5.69 \%$ had no cardiovascular risks factors.

Table 1: Distribution of study population as per Socio-demographic profile $(\mathrm{N}=\mathbf{2 4 6})$

\begin{tabular}{|l|c|c|}
\hline \multicolumn{1}{|c|}{$\begin{array}{c}\text { Socio demographic } \\
\text { profile }\end{array}$} & $\begin{array}{c}\text { Number } \\
(\mathbf{n})\end{array}$ & $\begin{array}{c}\text { Percentage } \\
(\boldsymbol{\%})\end{array}$ \\
\hline Age (in completed years) & & \\
\hline $25-34$ & 44 & 17.89 \\
\hline $35-44$ & 109 & 44.30 \\
\hline $45-54$ & 52 & 21.14 \\
\hline $55-64$ & 41 & 16.67 \\
\hline Gender & & \\
\hline Male & 166 & 67.48 \\
\hline Female & 80 & 32.52 \\
\hline
\end{tabular}

\begin{tabular}{|c|c|c|}
\hline \multicolumn{3}{|l|}{ Religion } \\
\hline Hindu & 202 & 82.11 \\
\hline Muslim & 44 & 17.89 \\
\hline \multicolumn{3}{|l|}{ Marital status } \\
\hline Single & 24 & 09.76 \\
\hline Married & 222 & 90.24 \\
\hline \multicolumn{3}{|l|}{ Highest education } \\
\hline M.B.B.S. & 13 & 05.29 \\
\hline MD & 187 & 76.01 \\
\hline MS & 20 & 08.13 \\
\hline DNB & 13 & 05.28 \\
\hline FRCP & 02 & 00.81 \\
\hline $\mathrm{PhD}$ & 11 & 04.48 \\
\hline \multicolumn{3}{|l|}{ Designation } \\
\hline Demonstrator & 85 & 34.56 \\
\hline Assistant Professor & 39 & 15.85 \\
\hline Associate Professor & 57 & 23.17 \\
\hline Professor & 59 & 23.98 \\
\hline HOD \& Professor & 06 & 02.44 \\
\hline \multicolumn{3}{|l|}{ Current residence } \\
\hline Rural & 02 & 00.81 \\
\hline Urban & 244 & 99.19 \\
\hline \multicolumn{3}{|l|}{ Type of family } \\
\hline Nuclear & 216 & 87.80 \\
\hline Joint & 30 & 12.20 \\
\hline \multicolumn{3}{|l|}{$\begin{array}{l}\text { Per Capita Monthly } \\
\text { Income (PCMI in Rs.) } \\
\text { (as per Modified B. G. } \\
\text { Prasad scale 2017) } \\
\end{array}$} \\
\hline Upper $(>=6254)$ & 242 & 98.37 \\
\hline $\begin{array}{l}\text { Upper middle }(3127 \text { - } \\
6253)\end{array}$ & 04 & 01.63 \\
\hline
\end{tabular}

Table 2: Distribution of study population as per discipline $(\mathrm{N}=246)$

\begin{tabular}{|l|c|c|}
\hline \multicolumn{1}{|c|}{ Department } & $\begin{array}{c}\text { Number } \\
\text { (n) }\end{array}$ & $\begin{array}{c}\text { Percentage } \\
(\mathbf{\%})\end{array}$ \\
\hline Anatomy & 30 & 12.20 \\
\hline Physiology & 12 & 04.88 \\
\hline Biochemistry & 28 & 11.38 \\
\hline Pathology & 14 & 05.69 \\
\hline Microbiology & 10 & 04.06 \\
\hline Ophthalmology & 07 & 02.84 \\
\hline Otolaryngology(ENT) & 09 & 03.68 \\
\hline General medicine & 15 & 06.10 \\
\hline General surgery & 22 & 08.94 \\
\hline Gynaecology \& & 14 & 05.69 \\
Obstetrics & & \\
\hline Paediatric Medicine & 22 & 08.94 \\
\hline Cardiology & 07 & 02.84 \\
\hline Orthopaedic surgery & 30 & 12.20 \\
\hline Community medicine & 07 & 02.84 \\
\hline Chest Medicine & 19 & 07.72 \\
\hline
\end{tabular}


Table 3: Distribution of the study population according to risk factors of cardiovascular disease $(\mathrm{N}=\mathbf{2 4 6}$ )

\begin{tabular}{|c|c|c|}
\hline Risk factors & $\underset{(\mathbf{n})}{\text { Number }}$ & $\begin{array}{c}\text { Percentage } \\
(\%)\end{array}$ \\
\hline \multicolumn{3}{|l|}{ Smoking status } \\
\hline Current smoker & 28 & 11.38 \\
\hline Former smoker & 33 & 13.42 \\
\hline Never smoker & 185 & 75.20 \\
\hline \multicolumn{3}{|l|}{$\begin{array}{l}\text { Number of cigarette } \\
\text { smoke/day }(\mathbf{N}=28)\end{array}$} \\
\hline$<10$ & 23 & 82.14 \\
\hline$>=10$ & 05 & 17.86 \\
\hline \multicolumn{3}{|l|}{$\begin{array}{l}\text { Duration of smoking } \\
\text { (years) }(\mathrm{N}=\mathbf{2 8})\end{array}$} \\
\hline$<1$ & 04 & 14.28 \\
\hline $1-5$ & 03 & 10.72 \\
\hline$>5-10$ & 04 & 14.28 \\
\hline$>10-20$ & 03 & 10.72 \\
\hline$>20$ & 14 & 50.00 \\
\hline \multicolumn{3}{|l|}{$\begin{array}{l}\text { Alcohol consumption } \\
\text { during last one year }\end{array}$} \\
\hline Yes & 37 & 15.04 \\
\hline No & 209 & 84.96 \\
\hline \multicolumn{3}{|l|}{$\begin{array}{l}\text { Frequency of alcohol } \\
\text { intake( }(\mathrm{N}=37)\end{array}$} \\
\hline Once in a week & 02 & 05.40 \\
\hline Once in a month & 17 & 45.95 \\
\hline Once in 1-3 months & 07 & 18.92 \\
\hline Once in 4-6 months & 11 & 29.73 \\
\hline \multicolumn{3}{|l|}{$\begin{array}{l}\text { Amount of alcohol in } \\
\text { one sitting }(\mathrm{ml})(\mathrm{N}=37)\end{array}$} \\
\hline $30-60$ & 15 & 40.54 \\
\hline$>60-90$ & 15 & 40.54 \\
\hline$>90$ & 07 & 18.92 \\
\hline \multicolumn{3}{|l|}{$\begin{array}{l}\text { Fast /Junk food } \\
\text { (days/week) }\end{array}$} \\
\hline $1-3$ & 119 & 48.37 \\
\hline $4-7$ & 33 & 13.41 \\
\hline Nil & 94 & 38.22 \\
\hline \multicolumn{3}{|l|}{$\begin{array}{l}\text { Fruit intake } \\
\text { (days/week) }\end{array}$} \\
\hline $1-3$ & 87 & 35.36 \\
\hline $4-7$ & 157 & 63.82 \\
\hline Nil & 02 & 00.82 \\
\hline \multicolumn{3}{|l|}{$\begin{array}{l}\text { Vegetable intake } \\
\text { (days/week) }\end{array}$} \\
\hline $1-3$ & 09 & 03.66 \\
\hline $4-7$ & 237 & 96.34 \\
\hline \multicolumn{3}{|l|}{ Cold drink (days/week) } \\
\hline $1-3$ & 135 & 54.87 \\
\hline $4-7$ & 43 & 17.49 \\
\hline Nil & 68 & 27.64 \\
\hline \multicolumn{3}{|l|}{ Family history of CHD } \\
\hline Yes & 48 & 19.51 \\
\hline No & 198 & 80.49 \\
\hline
\end{tabular}

\begin{tabular}{|l|c|c|}
\hline $\begin{array}{l}\text { Stressful event during } \\
\text { last one year }\end{array}$ & & \\
\hline Yes & 100 & 40.65 \\
\hline No & 146 & 59.35 \\
\hline $\begin{array}{l}\text { Vigorous intensity } \\
\text { activity (days/week) }\end{array}$ & & \\
\hline $1-3$ & 67 & 27.24 \\
\hline $4-7$ & 33 & 13.41 \\
\hline Nil & 146 & 59.35 \\
\hline $\begin{array}{l}\text { Vigorous intensity } \\
\text { activity } \\
\text { (min/day)(N=100) }\end{array}$ & & \\
\hline$<10$ & 63 & 63.00 \\
\hline $10-30$ & 28 & 28.00 \\
\hline$>30$ & 09 & 09.00 \\
\hline $\begin{array}{l}\text { Moderate intensity } \\
\text { activity (days/week) }\end{array}$ & & \\
\hline $1-3$ & 192 & 78.05 \\
\hline $4-7$ & 28 & 11.38 \\
\hline Nil & 26 & 10.57 \\
\hline $\begin{array}{l}\text { Moderate intensity } \\
\text { activity (mins/day)(N= } \\
\text { 220) }\end{array}$ & & \\
\hline $10-30$ & 107 & 48.64 \\
\hline$>30-60$ & 113 & 51.36 \\
\hline
\end{tabular}

Table 4: Distribution of the study population according to Physical Measurements( $\mathrm{N}=\mathbf{2 4 6})$

\begin{tabular}{|l|c|c|}
\hline \multicolumn{1}{|c|}{ BMI(WHO) } & $\begin{array}{c}\text { Number } \\
(\mathbf{n})\end{array}$ & $\begin{array}{c}\text { Percentage } \\
(\mathbf{\%})\end{array}$ \\
\hline Normal range & 159 & 64.63 \\
\hline Pre obese & 80 & 32.52 \\
\hline Obese class 1 & 07 & 02.85 \\
\hline $\begin{array}{l}\text { Waist circumference } \\
\text { (WHO) }\end{array}$ & & \\
\hline $\begin{array}{l}\text { Male(>=102 } \\
\text { cm.)(N=166) }\end{array}$ & 24 & 30.00 \\
\hline $\begin{array}{l}\text { Female (>=88 } \\
\text { cm,)(N=80) }\end{array}$ & & \\
\hline Waist : Hip & 33 & 19.88 \\
\hline Male (>1.00) & 32 & 40.00 \\
\hline Female (>0.85) & 46 & 18.70 \\
\hline Blood pressure & 178 & 72.36 \\
\hline Normal & 20 & 08.13 \\
\hline Pre -hypertension & 02 & 00.81 \\
\hline Hypertension stage 1
\end{tabular}


Table 5: Distribution of the study population according to Biochemical Measurements $(\mathrm{N}=246)$

\begin{tabular}{|l|c|c|}
\hline \multicolumn{1}{|c|}{$\begin{array}{c}\text { Biochemical } \\
\text { measurements }\end{array}$} & $\begin{array}{c}\text { Number } \\
(\mathbf{n})\end{array}$ & $\begin{array}{c}\text { Percentage } \\
(\mathbf{\%})\end{array}$ \\
\hline Fasting blood sugar (FBS) (mg/dl) \\
\hline $80-100$ (Normal) & 200 & 81.30 \\
\hline$>100-125($ Pre diabetic) & 22 & 08.94 \\
\hline$>=126$ (Diabetic) & 24 & 09.76 \\
\hline Total cholesterol (TC) (mg/dl) \\
\hline$<200($ Good) & 211 & 85.77 \\
\hline 200-239(Borderline) & 35 & 14.23 \\
\hline
\end{tabular}

Table 6: Distribution of study population as per number of cardiovascular risk factors $(\mathrm{N}=\mathbf{2 4 6})$

\begin{tabular}{|l|c|c|}
\hline Number of risk factors & $\begin{array}{c}\text { Number } \\
(\mathbf{n})\end{array}$ & $\begin{array}{c}\text { Percentage } \\
(\boldsymbol{\%})\end{array}$ \\
\hline $1-5$ & 213 & 86.59 \\
\hline $6-10$ & 17 & 06.91 \\
\hline $11-15$ & 02 & 00.81 \\
\hline Nil & 14 & 05.69 \\
\hline
\end{tabular}

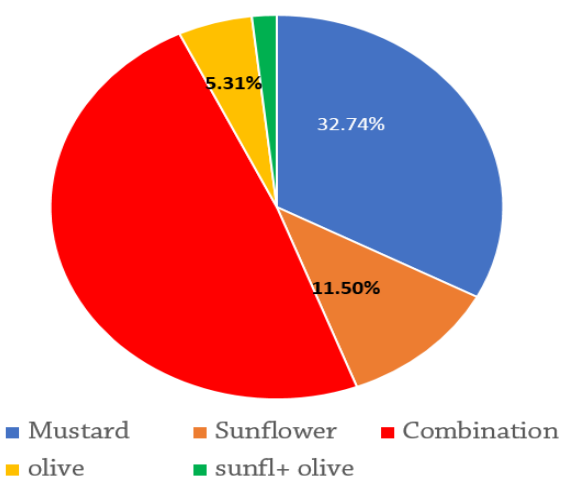

Fig. 1: Pie diagram showing type of oil used $(\mathrm{N}=246)$

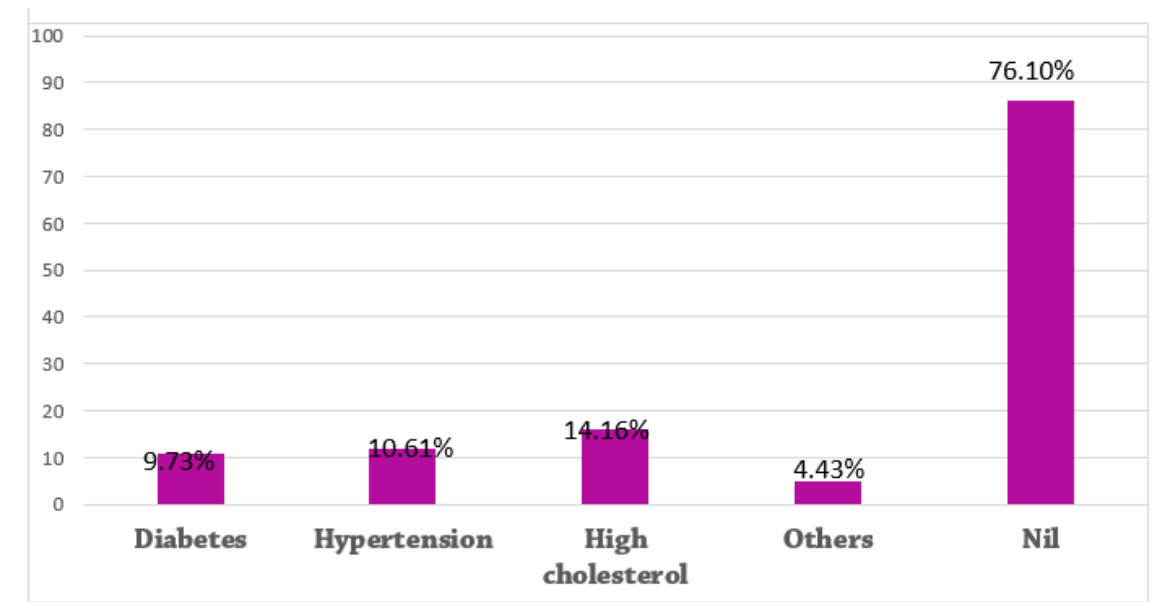

Fig. 2: Bar diagram showing self- reported disease*Multiple response

\section{Discussion}

The data from the present study showed considerable prevalence of cardiovascular risk factors among medical faculty members, which was in agreement with different national and international articles. ${ }^{15-20}$

In the present study, we found that $94 \%$ of the study population had one or more cardiovascular risk factors which was higher than a study done among medical students by Dangol et al at Lumbini Medical College Teaching Hospital, Nepal (88\%)..$^{15}$

Family history of cardiovascular disease, hypertension, and diabetes mellitus was reported by many of the participants of our study $(19.46 \%)$, which was similar to many other previous studies. ${ }^{15,19}$ A study by Nobahar et al at Iran reported almost similar results where family history of CVD was reported by $26.3 \%$ of the physicians, $16.1 \%$ of the nurses, and $24.2 \%$ of the faculty members. ${ }^{17}$ However study by Pasli et al at Turkey $^{16}$ among students studying in the Nursing, Nutrition \& Dietetics, and Physiotherapy \&Rehabilitation departments of the health sciences faculty of a university and Qureshi et al at Pakistan among doctors showed higher results $(31.9 \%$ \& $33.65 \%$ respectively). ${ }^{20}$

In this study, $9.73 \%, 10.61 \% \& 14.16 \%$ of the study population self -reported history of diabetes, hypertension and high cholesterol respectively. Ibrahim et al at Saudi Arabia ${ }^{18}$ revealed that $0.5 \%, 8.4 \%$ and $8.9 \%$ of medical students reported having diabetes, hypertension and hypercholesterolemia respectively. At Turkey H/O chronic diseases was $8.9 \%,{ }^{16}$ at Iran history 
of CVD was reported by $0.9 \%$, diabetes by $1.9 \%$, hypertension by $2.8 \%$, \& hyperlipidemia by $7.4 \% .{ }^{17}$ About $4.51 \%$ males and $3.10 \%$ females had self-reported diabetes at Ahmedabad. ${ }^{19}$

However $28.12 \%$ males and $30.20 \%$ females were suffering from different kind of NCDs in a study by Chhaya et al among Faculty Members of Teaching Institute of Ahmedabad. ${ }^{19}$ Surprisingly no one had diabetes, $6.2 \%$ were known hypertensive , \&1\% doctors had high cholesterol at Pakistan. ${ }^{20}$

About $11.38 \%$ of the study population were current smoker in this study; $8.4 \%$ smokers at Turkey, ${ }^{16} 1.8 \%$ at $\operatorname{Iran}^{17}, 2.8 \%$ at Saudi Arabia, ${ }^{18}$ and $5.21 \%$ at Ahmedabad. ${ }^{19}$

In this study, $89.43 \%$ of the study population did moderate intensity activity; this finding was similar to Iran $(90 \%),{ }^{17}$ and Ahmedabad $(79.51 \%$ males \& $75.60 \%$ females) ${ }^{19}$ but dissimilar to Turkey (43.2\%), ${ }^{16}$ Saudi Arabia(42.1\%), ${ }^{18}$ and Pakistan $(24 \%) .{ }^{20}$

About $99.18 \%$ of our study population ate fruits \& $96.34 \%$ took vegetables for 4-7 days in a week; the corresponding figures were $89 \% \& 45 \%$ at $\operatorname{Iran}^{17}$ and $17.8 \% \& 59.3 \%$ at Saudi Arabia. ${ }^{18}$

In the present study, $17.49 \%$ took soft drinks 4-7 days per week; similar to Saudi Arabia (21\%). ${ }^{18}$

Daily eating of fast food \& junk food was prevalent among $24.64 \%$ of faculty which was similar to Saudi Arabia. ${ }^{18}$ but much lower than Pakistan $(76 \%) .{ }^{20}$

It is a well-known fact that Anthropometric variables predict cardiovascular risk. A combination of BMI and central obesity can identify cardiovascular disease risk factors among adult patients. Thus we used BMI for obesity and waist circumference for central obesity in this study. After adjusting cut-off value for BMI and waist circumference as per WHO, we found $35.37 \%$ of participants of our study had higher BMI than the cut-off value and $26.51 \%$ male study population \& $30.00 \%$ female population had greater waist circumference than the cut-off. Nepal, ${ }^{15}$ Iran $(32.4 \%),{ }^{17}$ Saudi Arabia (31.8\%), ${ }^{18}$ and Ahmedabad study ${ }^{19}$ (30.55\% male \& $22.91 \%$ female) showed almost similar prevalence of obesity as per BMI. However it was much lower at Turkey $(12.2 \%){ }^{16}$ and quite higher at Pakistan $(53 \%) .^{20}$

We found that $8.94 \%$ of the study population were Hypertensive in the current study whereas the prevalence of high blood pressure was $2.8 \%$ in Iran $;{ }^{16} 9.3 \%$ in Saudi Arabia; ${ }^{17} 23.26 \%$ \& $26.38 \%$ in male \& female faculty members in Ahmedabad ${ }^{19}$ and systolic hypertension \& diastolic hypertension was $5.76 \%$ \& $5.28 \%$ respectively in Pakistan. ${ }^{20}$

$9.76 \%$ of our faculty were diabetic whereas it was $1.9 \%$ at Iran; $2.1 \%$ at Saudi Arabia ${ }^{18}$ and nil at Pakistan. $^{20}$

The impact of hypercholesterolaemia on cardiac function makes it a major public health concern globally. Increased total cholesterol was found nil in our study and
Nepal study $^{15}$ but high cholesterol seen in $21 \%$ in Pakistan. ${ }^{20}$

The medical faculty are mostly belong to affluent society, live a sedentary life, experience mental stress due to their duties which contribute to risk factors of CVDs. ${ }^{15-17,19}$

Like other studies, this study also had several limitations which included a small sample size, short time period and unable to collect data from some departments. Moreover study population might give socially desirable answers as it was a self- reporting questionnaire. The study was carried out in special group, hence it could not be representative of general population.

\section{Conclusions and Recommendations}

Our study revealed that $94 \%$ faculty members had one or more cardiovascular risk factors.

In this study, different types of cardiovascular risk factors were::male gender(67.48\%), smoking(11.38\%), alcohol consumption(15.04\%), fast food(13.14\%), junk food $(11.50 \%) \&$ cold drink (17.49\%)intake ,stress in last one year(40.65\%), family history of CVD(19.51\%), overweight \& obesity(35.37\%), pre hypertension(72.36\%) \& hypertension(8.94\%), diabetes $(9.76 \%)$, and high cholesterol.

Most common modifiable risk factor was prehypertension \& hypertension, followed by overweight \& obesity.

This small special group survey adds on the risk factors prevalent in the medical set-up and thus focuses the attention of cardiovascular epidemiologist and researcher to conduct more studies.

Hidden cases of hypertension revealed the lack of health seeking behavior among faculty members. The other modifiable risk factors such as physical inactivity, tobacco use, overweight, obesity, and stress needs sound address.

\section{Acknowledgement}

We are very much thankful to our respected faculty members who participated in the study and contributed their valuable reporting.

\section{References}

1. WHO. Media centre. Cardiovascular diseases(CVDs) Fact sheet. World Health Organization. Geneva. 2017. Available from http://www.who.int/mediacentre/factsheets/fs317/en/[ Accessed on 23.03.2018].

2. World Health Organization. WHO updates fact sheet on Cardio vascular diseases. Available from ttps://communitymedicine4asses.wordpress.com/2017/ 05/19/who-updates-fact-sheet-on-cardiovasculardiseases-18-may-2017/[Accessed on 23.03.2018].

3. Gupta R, Gupta S, Sharma KK, Gupta A, Deedwania PC. Regional variations in cardiovascular risk factors in India: India Heart Watch. World J Cardiol 2012;4:112-120. 
4. Prabhakaran D, Jeemon P, Roy A. Cardiovascular Diseases in India: Current Epidemiology and Future Directions. Circulation 2016;133(16):1605-20.

5. Registrar General of India. Report on Medical Certification of Cause of Death 2013. Office of the Registrar General, New Delhi, India 2015. Available from www.censusindia.gov.in/2011document/mccd_2013.pdf[Accessed on 30.03.2018].

6. WHO. The WHO STEPwise approach to chronic disease risk factor surveillance (STEPS). WHO STEPS Instrument (Core and Expanded). World Health Organization. Geneva. Switzerland. V3.1.Available from

http://www.who.int/ncds/surveillance/steps/STEPS_Ins trument_v2.1.pdf[Accessedon 31.03.2018].

7. Singh T, Sharma S, Nagesh S. Socio-economic status scales updated for 2017. Int J Res Med Sci 2017;5:3264-7.

8. CDC: Fact Sheet. Fast Facts. Smoking \& Tobacco Use. Centers for Disease Control and Prevention. Available from http://www.cdc.gov/tobacco/data_statistics/fact_sheets/ fast_facts/index.htm [Accessed on 24.03.2018].

9. Park K: Park's Textbook of Preventive and Social Medicine. $23^{\text {rd }}$ Edition. Banarsidas Bhanot Publishers. Jabalpur 2015:p613.

10. WHO: BMI Classification. Global Database on Body Mass Index. World Health Organization. 2006. Retrieved July 27, 2012.p3. Available from http://apps.who.int/ bmi/index.jsp. [Accessed on 25.03.2018].

11. WHO: Waist Circumference and Waist-Hip Ratio. Report of a WHO Expert Consultation. Geneva 8-11 December 2008. World Health Organization. 2011. p128. Available from http://whqlibdoc.who.int/publications/2011/978924150 1491_eng.pdf [Accessed on 26.03.2018].

12. Bell K, Twiggs J, Olin BR. Hypertension: The Silent Killer: Updated JNC-8 Guideline Recommendations. Alabama Pharmacy Association. summer 2015: Continuing eDuCAtion, Available from https://c.ymcdn.com/sites/aparx.siteym.com/resource/resmgr/CEs/CE_Hypertension_The_ Silent_K.pdf [Accessed on 25.04.2018].

13. WHO. Definition and Diagnosis of Diabetes Mellitus and Intermediate H.yperglycemia. World Health organization 2006.p 3. Available from http://www.who.int/diabetes/publications/Definition\% 20and\%20diagnosis\%20of\%20diabetes_new.pdf[Acce ssed on 24.04.2018].

14. WHO. Global Strategy on Diet, Physical Activity and Health 2017. Available from http://www.who.int/dietphysicalactivity/physical_activ ity_intensity/en/[Accessed on 25.04.2018].

15. Dangol RK, Koju B, Lanjekar P, Pulipati C.Cardiovascular Risk Factors among First Year Medical Students . Kournal of Lumbini Medical College 2017;5(2):64-68.

16. Pasli Gurdogan E et al. The Knowledge About Cardiovascular Risk Factors Among Students in a Faculty of Health Sciences.

17. Nobahar M, Razavi M R. Lifestyle and the Most Important Risk Factors of Cardiovascular Disease in Physicians, Nurses, and Faculty Members, Middle East J Rehabil Health. 2015 ;2(2): e28882. doi: 10.17795/mejrh-28882.

18. Ibrahim NK, Mahnashi M, Al-Dhaheri A, Al-Zahrani B, Al-Wadie E, Aljabri M, et al.Risk factors of coronary heart disease among medical students in King Abdulaziz University, Jeddah, Saudi Arabia. BMC Public Health 2014;14:411.

19. Chhaya J, Devalia J, Kedia G. Prevalence of Risk Factors and its Association with Non-communicable Disease among the Faculty Members of Teaching Institute of Ahmedabad City, Gujarat: A CrossSectional Study. Int J Sci Stud 2015;3(8):159-162.

20. Qureshi MS, Shah ST, Rehman H, Ali J , Khan SB ,Hadi A, et al. Frequency of Cardiovascular Disease Risk Factors among Doctors. Pak Heart J 2011;44 (0304):26-31. 